\title{
Consumer Search and Oligopolistic Pricing: \\ An Empirical Investigation
}

\author{
Maarten C.W. Janssen \\ José Luis Moraga-González* \\ Matthijs Wildenbeest
}

Department of Economics, Erasmus Universiteit Rotterdam, and Tinbergen Institute.

* CESifo. 


\section{Tinbergen Institute}

The Tinbergen Institute is the institute for economic research of the Erasmus Universiteit Rotterdam, Universiteit van Amsterdam, and Vrije Universiteit Amsterdam.

Tinbergen Institute Amsterdam

Roetersstraat 31

1018 WB Amsterdam

The Netherlands

Tel.: $\quad+31(0) 205513500$

Fax: $\quad+31(0) 205513555$

Tinbergen Institute Rotterdam

Burg. Oudlaan 50

3062 PA Rotterdam

The Netherlands

Tel.: $\quad+31(0) 104088900$

Fax: $\quad+31(0) 104089031$

Please send questions and/or remarks of nonscientific nature to driessen@tinbergen.nl.

Most TI discussion papers can be downloaded at http://www.tinbergen.nl. 


\title{
Consumer Search And Oligopolistic Pricing: An EMPIRICAL INVESTIGATION*
}

\author{
Maarten C. W. Janssen ${ }^{\dagger} \quad$ José Luis Moraga-González ${ }^{\ddagger} \quad$ Matthijs R. Wildenbeest ${ }^{\S}$
}

First version: June 2004

\begin{abstract}
This paper presents an empirical examination of oligopoly pricing and consumer search. The theoretical model allows for sequential and non-sequential search and using the theoretical restrictions firm and consumer behavior impose on the data we study the empirical validity of the models. Two equilibria arise: one with costless search and the other with costly search. We find that the costless search equilibrium works well for products with a relatively low value, and, by implication, a small number of sellers. By contrast, the costly search equilibrium explains the observed data in a manner that is consistent with the underlying theoretical model for almost all products (for 86 out of 87 !).
\end{abstract}

Keywords: consumer search, oligopoly, price dispersion, maximum likelihood estimation

JEL Classification: C13, D40, D83, L13

\footnotetext{
${ }^{*}$ We thank Zsolt Sandor and Aico van Vuuren for their useful comments. Address for correspondence: Erasmus University Rotterdam, Department of Economics, Office H07-26, Postbox 1738, 3000 DR Rotterdam, The Netherlands. Fax: ++31-10-4089149.

${ }^{\dagger}$ Erasmus University and Tinbergen Institute, E-mail: <janssen@few.eur.nl>

${ }^{\ddagger}$ Erasmus University, Tinbergen Institute and CESifo, E-mail: <moraga@few.eur.nl>

${ }^{\S}$ Erasmus University and Tinbergen Institute, E-mail: <wildenbeest@few.eur.nl>.
} 


\section{Introduction}

This paper intends to study the empirical usefulness of theoretical search models. For this purpose, we take a simple model originally presented in Stahl (1989) and allow for sequential and non-sequential search. ${ }^{1}$ An important feature of the model is that there are two types consumers, namely, consumers whose opportunity cost of time is zero and thus are fully informed, and uninformed consumers who get a first price quotation for free and who face positive search costs for each additional search. ${ }^{2}$ This simple model accommodates two of the most frequently encountered equilibria in the search literature. In particular, the model has an equilibrium where uninformed consumers search for one price and then stop searching as the benefits of an additional search are smaller than the search cost. This is the equilibrium discussed in Stahl (1989) and it also arises under non-sequential search when the search cost is high compared to the value of the purchase. We refer to this equilibrium as the costless search equilibrium. A second type of equilibrium has uninformed consumers randomizing between searching for one price and searching for two prices. We call this equilibrium a costly search intensity equilibrium to distinguish it from the case in which buyers sample just one firm. It arises, for example, in the non-sequential search literature when search costs are low enough (cf., Burdett and Judd, 1983). Both equilibria exhibit price dispersion.

In line with the main aim of the paper, we consider the empirical predictions of the different equilibria and ask the question whether the above simple model can explain observed price dispersion and if so, which of the two equilibria presented above seems to accommodate observed data better. In particular, we try to stay close to the theoretical model and use the following methodology. The two equilibria yield different functional forms of the price distributions to be expected in the market, as well as theoretical restrictions on those distributions for consumer search to be optimal. We use this information (price equations and optimal search conditions) to estimate the parameters of the theoretical models, in particular the fraction of zero-cost consumers, search intensity, marginal cost and search cost. For this aim, we gather price data from on-line markets using shopper.com, an American based search engine. We focus on the market for computer hardware and peripherals, in particular on keyboards, mice, memory chips and computer cables. In total we

\footnotetext{
${ }^{1}$ Papers like McAfee (1995) and Reinganum (1979) are in the sequential search tradition; whereas Acemoglu and Shimer (2000), Burdett and Judd (1983) and Janssen and Moraga-González (2004) follow the non-sequential paradigm. Morgan and Manning (1985) study the question which paradigm is more appropriate under quite general circumstances concerning the delay with which consumers get the information they are searching for.

${ }^{2}$ The assumption that consumers obtain the first price observation for free is common in the search literature (see e.g. Burdett and Judd, 1983 and Stahl, 1989). Janssen and Moraga-González (2004) present a search model where all price observations are costly. For the implications of this alternative assumption in the present paper see footnote 8 below.
} 
examine markets for 87 products and a common feature we see is that prices are quite dispersed. ${ }^{3}$ Using these price data we estimate (by maximum likelihood) the different models and test whether the equilibria described above are consistent with the price observations we gathered.

Our first observation is that it is difficult to empirically distinguish between the sequential search model and the non-sequential search model provided that consumers sample just one firm. The reason is that the equations that characterize firm price setting are empirically identical in these two cases.

Secondly, we examine the empirical performance of the costless search equilibrium. We find that the restrictions this equilibrium imposes on the data are always rejected when the value of the purchase is large enough. Indeed, this equilibrium is rejected for all but two memory chips, for all but one keyboard whose average price is above $\$ 40-\$ 45$, for all mice with an average price above $\$ 35$ and for 5 out of 11 cables of similar value. By contrast, when the value of the purchase is low the costless search equilibrium performs much better. For example, this equilibrium cannot be rejected for 9 out of 10 low-valued computer cables, nor for 5 out of 8 low-priced keyboards, nor for 7 out of 10 cases in the markets for inexpensive mice. This evidence suggests that the costless search equilibrium is useful in markets where the value of the purchase is low, a prediction that is in line with the theoretical models we examine in this paper.

As to the empirical performance of the costly search equilibrium, we find that this equilibrium cannot be rejected in almost all cases (for 86 out of 87 products!). The estimates of the parameters of the costly search equilibrium also seem to be of reasonable magnitude. For example, in the markets for computer memory, the estimated fraction of consumers who search at no cost ranges from $4 \%$ to around $63 \%$ and are in most cases significant; likewise, the estimates of the number of captive consumers who search just once ranges from $23 \%$ to $74 \%$, and are in all cases highly significant.

Finally, when comparing the empirical performance of the costly search and the costless search equilibria we see that likelihood scores are always higher for the former than for the latter. This implies that the costly search equilibrium outperforms the alternative equilibrium. This is reasonable because the model with costly search includes a set of consumers who search for two prices and this extra variable gives this equilibrium more flexibility vis-à-vis the costly search one. To see if the addition of an extra parameter is empirically justified, we run a likelihood ratio test. We

\footnotetext{
${ }^{3}$ Baye, Morgan and Scholten (2001) examine price data for 1000 consumer electronics over an 8-month period. They find strong support for the idea that price dispersion is ubiquitous in on-line markets and a stable feature over time.
} 
find that, for example in the market for keyboards, at a 5\% significance level the null hypothesis that the models are equal is always rejected. This strongly suggests that the costly search intensity equilibrium yields a better explanation of observed price dispersion than the other type of equilibrium. ${ }^{4}$

Our paper is a contribution to the study of the empirical relevance of search models, and more in general price dispersion models. Some studies have found that price dispersion is negatively related to low search costs and high benefits from search (see e.g. Brown and Goolsbee, 2002; Brynjolfsson and Smith, 2000; Clay, Krishnan and Wolff, 2001 and Sorensen, 2000 and 2001). Our paper differs from this work in that we employ the explicit theoretical restrictions that are obtained from a consumer search and oligopolistic pricing model to test its empirical validity. This is a more direct test of its usefulness and we find that the fit between the data and the costly search equilibrium is remarkably good. Villas-Boas (1995) used a related approach to assess the empirical usefulness of Varian's (1980) model of sales using data from the coffee and saltine crackers markets. He found the model rejected for $66 \%$ of the coffee brands and for $50 \%$ of the crackers brands. This high percentage of rejection is consistent with our findings on the costless search equilibrium. The analysis in our paper is closely related to recent work by Hong and Shum (2004), who present a useful methodology to estimate search cost distributions on the basis of price data alone. An important difference between their paper and ours is that our theoretical model allows for both sequential and non-sequential search, which enables us to stick to the same estimation method and directly compare the empirical results of the two search protocols. In their article the models they estimate are different and also the estimation techniques, which makes a direct comparison between the models difficult. Another important difference is that while they examine competitive models, i.e., models where there are infinitely many firms in the market, we study the more realistic case of oligopoly. As shown in Janssen and Moraga-González (2004) and Stahl (1989), firm pricing becomes more monopolistic when the number of firms increases, and this discourages search. We finally note that while Hong and Shum estimate a search cost distribution with continuous support, we estimate a two point distribution including an atom of consumers whose opportunity cost of time is zero and thus sample all the stores before buying. Including an atom of zero-search-cost consumers is important on theoretical grounds since it guarantees existence and uniqueness of equilibrium under sequential search (Stahl, 1996) but also on empirical grounds since, according to Whelan (2001), Internet shoppers are increasingly falling into two types: bargain hunters who visit as many shops

\footnotetext{
${ }^{4}$ Moreover, we note that the costless search equilibrium yields estimates of the percentage of fully informed consumers that seem much too high.
} 
as possible and brand loyalists who just visit one or two shops.

Our paper is also related to recent experimental work on price dispersion and, in particular, on search models. Morgan, Orzen and Sefton (2003) test a model similar to Varian (1980) in the laboratory. Price dispersion arises in the experimental data and the comparative statics effects of key parameter changes conform very well with the theory. However, there seems to be a systematic bias in the sense that subjects tend to charge higher prices than what the theoretical model predicts. We note that Varian's model and our costless search model are observationally equivalent so our result that this model does not perform very well is in line with this latter finding in the lab. Abrams, Sefton and Yavas (2000) designed an experiment to investigate markets with consumer search. In particular, they focused on the extreme cases known as Diamond and Bertrand paradoxes. In a first treatment they provided each buyer with information about a single price. In this situation equilibrium predicts that sellers charge the monopoly price and buyers abstain from searching. In a second treatment they informed buyers of two prices, which leads to the prediction that firms use marginal cost pricing and again buyers do not search. They found a clear effect of information provision on the level of equilibrium prices. However, they pointed out a divergence between observed and predicted prices and argued that this is consistent with ultimatum game experiments. ${ }^{5}$ Cason and Friedman (2003) present a laboratory study based on the 'noisy search model' of Burdett and Judd (1983). The model fared very well in predicting the extent of price dispersion and the comparative statics of higher search costs and larger sample sizes. However, as in Abrams et al. (2000), Cason and Friedman also found systematic differences between the empirical data and the theoretical prediction, in particular, subjects tended to quote higher prices more frequently than what was expected on the basis of the theory. The authors also found that tests of the goodness of fit strongly rejected the null hypothesis that the data come precisely from the theoretical distribution. Finally, Baye and Morgan (2004) propose two bounded rationality theories to reconcile the observed departure from Nash-behavior in the experiments of Abrams, Sefton and Yavas (2000) and Dufwenberg and Gneezy (1998). The predictions derived from the bounded rationality models explain the experimental data much better that Bertrand-Nash and random pricing and the bounded rationality models are not rejected often.

The paper is organized as follows. Section 2 describes in more detail the model we use. Section 3 provides a complete characterization of the equilibria that arise for distinct parameter constellations, for both search protocols. Section 4 discusses the data we have collected, the empirical methodology and the results. Section 5 concludes.

\footnotetext{
${ }^{5}$ Davis and Holt (1996) obtained similar results in a related experimental analysis.
} 


\section{The Model}

We examine a model of oligopolistic competition in the presence of consumer search. The model is similar to Stahl (1989), but we examine both sequential and non-sequential search. On the supply side of the market there are $N$ firms. Firms produce the good at constant returns to scale and their identical unit cost is equal to $r$. On the demand side of the market, there is a unit mass of buyers who wish to purchase at most a single unit of the good. We assume that a proportion $\lambda \in(0,1)$ of the consumers has negligible opportunity cost of time and therefore search for prices costlessly. ${ }^{6}$ We will refer to these buyers as informed. ${ }^{7}$ The other $1-\lambda$ percent of the buyers, referred to as uninformed, must pay search $\operatorname{cost} c>0$ to observe every price quotation beyond the first one. ${ }^{8}$ These consumers may search either sequentially (á la Stahl, 1989) or non-sequentially (á la Burdett and Judd, 1983). Under sequential search, a buyer decides whether to sample a second firm or not upon observation of the price of the first firm, and so on. Under non-sequential search, buyers decide how many prices to observe before purchasing from the store with the lowest observed price. ${ }^{9}$ After consumers search optimally, they buy the good from the lowest priced store in their sample. We assume that the maximum price any buyer is willing to pay for the good is $v .^{10}$ The ratio $(v-r) / c$ determines the type of equilibrium one encounters under non-sequential search and we shall refer to it as the relative value of the purchase (for an uninformed buyer).

Firms and buyers play a simultaneous move game. An individual firm chooses its price taking price choices of the rivals as well as consumers' search behavior as given. Likewise, an individual buyer forms conjectures about the distribution of prices in the market and decides on his/her optimal search strategy. We shall look for symmetric Nash equilibria. ${ }^{11}$ Let us denote the distribution of prices charged by a firm by $F(p)$.

\footnotetext{
${ }^{6}$ An atom of "shoppers" guarantees existence and uniqueness of symmetric Nash equilibrium in mixed strategies when consumers search sequentially (see Stahl, 1996).

${ }^{7}$ We regard the proportion of informed consumers $\lambda$ as the proportion of consumers making use of a shopbot. Shopbots make it very easy for consumers to save time and money as they can see in just a few mouse clicks which shop is the cheapest, whereafter they need just another few clicks to conduct the purchase.

${ }^{8}$ Relaxing this assumption leads to a new equilibrium where less informed consumers do not enter the market with positive probability. While this equilibrium has interesting properties (see Janssen, Moraga-González and Wildenbeest, 2004), it is observationally equivalent to the costless search equilibrium. This is easily seen as in the relevant equations describing the equilibrium price distribution, $(1-\lambda)$ is replaced by $\mu(1-\lambda)$, where $\mu$ is the probability that uninformed consumers do search once. Without a priori restrictions on $\mu$ and/or $\lambda$, one cannot get independent estimates for these parameters.

${ }^{9}$ See Morgan and Manning (1985) for a discussion of the advantages and disadvantages of these search methods.

${ }^{10}$ The assumption of inelastic demands is not restrictive in the markets we focus on in our empirical part, namely, keyboards, mice, computer cables and memory chips.

${ }^{11}$ As pointed out in Baye, Kovenock and de Vries (1992), there may exist asymmetric equilibria but the symmetric one is the most reasonable equilibrium in these settings.
} 


\section{Equilibria}

\subsection{Consumers' equilibrium behavior}

The theoretical results follow Stahl (1989) and Janssen and Moraga-González (2004). Since the equilibrium restrictions will be used in the empirical strategy, here we gather these results. Our first observation is that, irrespective of the search protocol, consumers will not search much in equilibrium.

Lemma 1 (a) Assume that uninformed consumers search sequentially; then they will not search beyond the first firm. (b) Assume that uninformed consumers search non-sequentially; then they will not search for three prices or more with positive probability, nor for two prices with probability one.

Proof. For (a), see Lemma 2 of Stahl (1989). For (b), see Lemma 1 of Janssen and MoragaGonzález (2004).

We now introduce some notation that we will use throughout the paper. Let $\mu_{1}$ be the probability with which an uninformed buyer searches for a price quotation. Lemma 1 implies that if consumers search sequentially only one candidate for equilibrium exist: $\mu_{1}=1$. In this case we shall say that they search costlessly.

For the case of non-sequential search, Lemma 1 implies that there may be two equilibria. Using the same notation as above, we can have either: (a) $\mu_{1}=1$, or (b) $\mu_{1}+\mu_{2}=1,0<\mu_{2}<1$, where $\mu_{2}$ denotes the probability with which a buyer searches for 2 price quotations. When $\mu_{2}>0$ in equilibrium, we shall say that there is a costly search equilibrium.

We now notice that $\mu_{1}>0$ in any equilibrium, regardless of whether buyers search sequentially or non-sequentially; this implies that:

Lemma 2 Irrespective of the search behavior of uninformed consumers, if $F(p)$ is an equilibrium price distribution, then it is atomless. Hence, there is no pure strategy equilibrium.

Proof. See, e.g., Lemma 1 of Stahl (1989).

This result shows that equilibria must necessarily exhibit price dispersion, and that firm pricing is characterized by atomless price distributions in any case. In what follows we shall examine the characterization and the existence of different equilibria, both under sequential and non-sequential search. After this, we shall use the theoretical restrictions optimal pricing and optimal consumer 
search impose on the market to estimate parameters and to test the empirical usefulness of the different models.

\subsection{Firms' equilibrium behavior}

\section{Case a: Costless search}

First assume that uninformed buyers search for one price with probability 1, i.e., $\mu_{1}=1$. In such case, the expected payoff to firm $i$ from charging price $p_{i}$ when its rivals choose a random pricing strategy according to the cumulative distribution $F(\cdot)$ is

$$
\pi_{i}\left(p_{i}, F\left(p_{i}\right)\right)=\left(p_{i}-r\right)\left[\frac{1-\lambda}{N}+\lambda\left(1-F\left(p_{i}\right)\right)^{N-1}\right]
$$

This profit expression is easily understood. Firm $i$ obtains a per consumer profit of $p_{i}-r$. The expected demand faced by a firm stems from the two different groups of consumers. Firm $i$ attracts the $\lambda$ informed consumers when it charges a price that is lower than its rivals', which happens with probability $\left(1-F\left(p_{i}\right)\right)^{N-1}$. The firm also serves the $1-\lambda$ uninformed consumers whenever they they visit its store, which occurs with probability $1 / N$.

In equilibrium, a firm must be indifferent between charging any price in the support of $F(\cdot)$. Let us denote the upper bound of $F(\cdot)$ by $\bar{p}$. Any price in the support of $F(\cdot)$ must then satisfy $\pi_{i}\left(p_{i}, F(\cdot)\right)=\pi_{i}(\bar{p})$, i.e.,

$$
\left(p_{i}-r\right)\left[\frac{1-\lambda}{N}+\lambda\left(1-F\left(p_{i}\right)\right)^{N-1}\right]=\frac{(1-\lambda)(\bar{p}-r)}{N}
$$

Solving this equation for the price distribution yields

$$
F(p)=1-\left(\frac{(1-\lambda)(\bar{p}-p)}{N \lambda(p-r)}\right)^{\frac{1}{N-1}}
$$

Since $F$ is a distribution function there must be some $\underline{p}$ for which $F(\underline{p})=0$. Solving for $\underline{p}$ one obtains the lower bound of the price distribution

$$
\underline{p}=\frac{(1-\lambda)(\bar{p}-r)}{\lambda N+(1-\lambda)}+r
$$

The price distribution (3) represents optimal firm pricing irrespective of whether uninformed buyers search sequentially or non-sequentially. What distinguishes these two is the maximum price $\bar{p}$ firms will charge. Consider first the non-sequential search setting. The maximum price a firm will 
ever charge is $v$ since no buyer who observed a price above his/her reservation price would acquire the good. Further, the upper bound of the price distribution cannot be lower than $v$ because a firm charging the upper bound would gain by slightly raising its price. Thus, under non-sequential search, it must be the case that $\bar{p}=v$, with $F(v)=1$ and $F(p)<1$, for all $p<v$.

In the sequential search setting, things are slightly more complicated. Consider a buyer who has observed a given price $p$. This consumer will continue searching if the expected benefits from continued search exceed the search costs. We can define the reservation price $\rho$ as the price that makes a consumer indifferent between searching once more and accepting the price at hand; this price satisfies:

$$
\int_{\underline{p}}^{\rho}(\rho-p) f(p) d p=c .
$$

It is obvious that no firm will charge a price above $\rho$ since this will lead to continued search. As a result, under sequential search, the upper bound $\bar{p}=\rho$. We now derive an expression for $\rho$. Rewriting equation (5) gives

$$
\rho[F(\rho)-F(\underline{p})]-\int_{\underline{p}}^{\rho} p f(p) d p=c .
$$

Since $F(\rho)=1, F(\underline{p})=0$ and $\int_{\underline{p}}^{\rho} p f(p) d p=E[p]$, equation (6) can be rewritten as

$$
\rho-E[p]-c=(\rho-r)-(E[p]-r)-c=0
$$

To calculate $E[p]-r$ we solve equation (3) for $p-r$, which gives

$$
p-r=\frac{\rho-r}{1+b N(1-F)^{N-1}}
$$

where $b=\lambda /(1-\lambda)>0$. We note now that $E[p]-r=\rho-r-\int_{\underline{p}}^{\rho} F(p) d p$. By changing variables we can write $E[p]-r=\int_{0}^{1}(p-r) d y$. Plugging $p-r$ from equation (8) gives, after rewriting,

$$
E[p]-r=(\rho-r) \int_{0}^{1} \frac{d y}{1+b N y^{N-1}}
$$

Equation (9) can be plugged into equation (7) to solve for $\rho$ :

$$
\rho=\frac{c}{1-\int_{0}^{1} \frac{d y}{1+b N y^{N-1}}}+r
$$

We note that the reservation price $\rho$ increases in $c$, decreases in $\lambda$ and is insensitive to $v$. This 
equilibrium exists for all parameters. We will use equations (3), (4), and (10) to estimate the parameters of the model.

In case consumers search non-sequentially, equilibrium existence requires, that uninformed consumers prefer searching once over searching twice, i.e., $v-E\left[\min \left\{p_{i}, p_{j}\right\}\right]-c<v-E[p]$, for all $i, j \in N$. This condition can be rewritten as

$$
\int_{0}^{1} \frac{2 y-1}{1+b N(1-y)^{N-1}} d y<\frac{c}{v-r}
$$

and will be used to estimate the non-sequential costless search equilibrium along with equations (3) and (4). For future reference, let us denote the left-hand-side of equation (11) as $\Gamma(1 ; \lambda ; N) .{ }^{12}$ We note that $0<\Gamma(1 ; \lambda ; N)<1$ for all parameters. Then we can state:

Proposition 1 (a) A sequential costless search equilibrium exists where buyers search for one price and firms charge prices from the set $[(1-\lambda)(\rho-r) /(\lambda N+(1-\lambda))+r, \rho]$ according to the price distribution

$$
F(p)=1-\left(\frac{(1-\lambda)(\rho-p)}{N \lambda(p-r)}\right)^{\frac{1}{N-1}}
$$

where $\rho$ solves equation (10). (b) Let $\Gamma(1 ; \lambda ; N)<\frac{c}{v-r}$. Then a non-sequential costless search equilibrium exists where firms charge prices from the set $[(1-\lambda)(v-r) /(\lambda N+(1-\lambda))+r, v]$ according to the price distribution

$$
F(p)=1-\left(\frac{(1-\lambda)(v-p)}{N \lambda(p-r)}\right)^{\frac{1}{N-1}}
$$

It is readily seen that the price distribution under non-sequential search dominates in a firstorder stochastic sense the price distribution under sequential search. This illustrates the influence consumers' threat to search further has on price setting.

\section{Case b: Costly search}

Assume that uninformed consumers randomize between searching for one price quotation with probability $\mu_{1}$, and searching for two price quotations with probability $\mu_{2}=1-\mu_{1} \cdot{ }^{13}$ As argued above, this case only arises under non-sequential search. The expected payoff to firm $i$ is

$$
\pi_{i}\left(p_{i}, F(p)\right)=\left(p_{i}-r\right)\left[\lambda\left(1-F\left(p_{i}\right)\right)^{N-1}+\frac{2(1-\lambda)\left(1-\mu_{1}\right)}{N}\left(1-F\left(p_{i}\right)\right)+\frac{(1-\lambda) \mu_{1}}{N}\right]
$$

\footnotetext{
${ }^{12}$ The number 1 in the arguments of $\Gamma(\cdot)$ stands for $\mu_{1}=1$.

${ }^{13}$ For ease of exposition, we maintain the notation used so far in the sense that $\mu_{1}$ denotes the probability with which uninformed buyers search for one price.
} 
Again, firm $i$ makes a per consumer profit of $p_{i}-r$ and expected demand stems from three different groups of customers: informed consumers, uninformed consumers who observe two prices and uninformed consumers who observe just a single price.

In equilibrium, a firm must be indifferent between charging any price in the support of $F$. The arguments above imply that $F(v)=1$, and $F(p)<1$, for all $p<v$. Any price in the support of $F$ must satisfy $\pi_{i}\left(p_{i}, F(\cdot)\right)=\pi_{i}(v)$, i.e.,

$$
(p-r)\left[\frac{(1-\lambda) \mu_{1}}{N}+\frac{2(1-\lambda)\left(1-\mu_{1}\right)}{N}(1-F(p))+\lambda(1-F(p))^{N-1}\right]=\frac{\mu_{1}(1-\lambda)(v-r)}{N} .
$$

Equation (13) cannot be solved for $F(p)$ for general values of $N$, but by setting $F(p)=0$, the lower bound of the price distribution can be found:

$$
\underline{p}=\frac{\mu_{1}(1-\lambda)(v-r)}{(1-\lambda)\left(2-\mu_{1}\right)+N \lambda}+r
$$

The final step is to confront equation (13) with optimal search behavior of the uninformed consumers. A mixed strategy over the support $[\underline{p}, v]$ according to the cumulative distribution function $F$, which solves (13), is optimal if and only if uninformed consumers are indeed indifferent between searching for only one price and searching for two prices. Therefore, it must be the case that $v-E\left[\min \left\{p_{i}, p_{j}\right\}\right]-2 c=v-E[p]-c$, for all $i, j \in N$. In other words, the following must hold:

$$
\int_{0}^{1} \frac{2 y-1}{1+2\left(\frac{1}{\mu_{1}}-1\right)(1-y)+\frac{1}{\mu_{1}} b N(1-y)^{N-1}} d y=\frac{c}{v-r} .
$$

Let $\Gamma\left(\mu_{1}, \lambda, N\right)$ denote the LHS of equation (15). We note that $\Gamma(0, \lambda, N)=0$. Moreover, $\Gamma\left(\mu_{1}, \lambda, N\right)$ is positive for all $\mu_{1}$, and concave in $\mu_{1}$. Let $\bar{\Gamma}\left(\mu_{1}, \lambda, N\right)=\max _{\mu_{1} \in(0,1]} \Gamma\left(\mu_{1}, \lambda, N\right) .{ }^{14}$ Then:

Proposition 2 Let $0<\frac{c}{v-r}<\bar{\Gamma}\left(\mu_{1}, N, \lambda\right)$. Then, there exist at least one and at most two symmetric costly search equilibria. In equilibrium, consumers search with a high intensity $\mu_{1}^{*} \in(0,1)$ given by the solution to equation (15) and firms randomly select prices from the set $\left[\frac{\mu_{1}^{*}(1-\lambda) v}{N \lambda+(1-\lambda)\left(2-\mu_{1}^{*}\right)}+r, v\right]$ according to the price distribution that solves equation (13).

For some parameters, there may be two equilibria. They differ in the probability with which consumers search for two prices. Fershtman and Fishman (1992) have pointed out that only the equilibrium where consumers search for two prices with higher probability is stable. In the remain-

\footnotetext{
${ }^{14}$ See Janssen and Moraga-González (2004) for a derivation of equation (15) and these properties.
} 
ing of the paper, we shall focus on this stable equilibrium. We shall use equations (13), (14) and (15) to estimate the costly search equilibrium.

In summary, under non-sequential search there are two equilibria. If search cost is large consumers search for one price with probability one. When search cost is low buyers search more in equilibrium. This yields two important insights. $(i)$ For a fixed $\lambda$, consumers tend search more in markets where the relative value of the purchase is larger. (ii) For a fixed $c /(v-r)$, consumers tend to search more in markets with more informed buyers. Despite the difficulties to observe buyers search intensity in real-world markets, casual evidence tells us that an individual buyer searches more in some markets than in others. This casual observation is confirmed by Johnson et al.(2004) who find that on the Web $70 \%$ of CD shoppers, $70 \%$ of book purchasers and $36 \%$ of travel buyers were observed to visit just one site. Since consumers search activity feeds back into firm pricing behavior and vice versa, our empirical research shall shed light on whether consumers search much or little in equilibrium.

\section{Empirical Analysis}

\subsection{Estimation}

In this subsection we discuss the estimation procedure by maximum likelihood. The empirical strategy is as follows. For a given product and a given cross-section price data, we first obtain an estimate of the different theoretical density functions that correspond to the distinct search equilibria. Next, we test which of the density functions is most likely and whether it is probable that the empirical price distributions for each product are drawn from the estimated theoretical distribution functions.

In order to estimate the different search equilibria, we first derive the density functions associated with the equilibrium price distributions given in equations (3) and (13). The density function for the costless search equilibrium is

$$
f(p)=\frac{1}{N-1}\left(\frac{\bar{p}-p}{p-r}\right)^{\frac{2-N}{N-1}}\left(\frac{1-\lambda}{N \lambda}\right)^{\frac{1}{N-1}} \frac{\bar{p}-r}{(p-r)^{2}},
$$

where $\bar{p}$ is either $v$ or $\rho$ depending on which search protocol is assumed. As we will explain in more detail later, in order to get consistent estimates of the unknown parameters of the model, we shall take $v$ or $\rho$ as known and equal to the upper bound of the observed price distribution. This implies that the only way to distinguish between the sequential and the non-sequential search protocols 
is to impose a priori restrictions on the level of search costs and compare the estimates equations (10) and (11) yield.

As we pointed out above, the density function for the costly search equilibrium cannot be derived analytically for general values of $N$. Nevertheless, using the implicit function theorem in equation (13), we can obtain an expression for $f(p)$ as a function of $F(p)$ :

$$
f(p)=\frac{\lambda N(1-F(p))^{N-1}+2(1-\lambda)\left(1-\mu_{1}\right)(1-F(p))+(1-\lambda) \mu_{1}}{(p-r)\left(\lambda N(N-1)(1-F(p))^{N-2}+2(1-\lambda)\left(1-\mu_{1}\right)\right)} .
$$

We shall solve equation (13) numerically for $F(p)$ and use it in equation (17) to obtain the density function.

To investigate which of the search equilibria (the costly or the costless search equilibrium) gives a better description of the data, it is important to notice that these two equilibria are empirically nested, i.e., the costless search equilibrium is a special case of the costly search equilibrium. This can easily be seen by setting $\mu_{1}=1$ and plugging equation (13) into equation (17), which will give a density function equal to equation (16).

We set the number of firms $N$ equal to the number of price observations found in the data. The objective is to maximize the log-likelihood function, which is given by $L L=\sum_{i=1}^{N} \log f\left(p_{i}\right)$. Because the support of the log-likelihood function depends upon unknown parameters, maximum likelihood estimation is not standard. Following Kiefer and Neumann (1993) we take the sampling minimum and maximum to estimate $\underline{p}$ and $\bar{p}$, respectively. ${ }^{15}$ These super-consistent estimates allow us to proceed as if $p$ and $\bar{p}$ were known. Using $p$ and $\bar{p}$ in (4) and (14) yield expressions which can be solved for the marginal cost $r$. This gives $r=\underline{p}-(1-\lambda)(\bar{p}-\underline{p}) / \lambda N$ in the case of costless search, and $r=\underline{p}-\mu_{1}(1-\lambda)(\bar{p}-\underline{p}) /\left(\lambda N+2(1-\lambda)\left(1-\mu_{1}\right)\right)$ in the costly search equilibrium. Plugging these values in equations (16) and (17) allows us to eliminate $r$ from the density functions so that maximum likelihood can be applied. The parameters left for estimation are $\lambda$ for the case of costless search, and $\lambda$ and $\mu_{1}$ for the case of costly search.

We use the Broyden, Fletcher, Goldfarb and Shanno (BFGS) quasi-Newton method with a mixed quadratic and cubic line search procedure to find the combination of $\lambda$ and $\mu_{1}$ that maximizes $L L$ given $N$, the consistent estimates of $\underline{p}$ and $\bar{p}$ and the vector of remaining prices, i.e, all the prices apart from the maximum and the minimum price. The BFGS quasi-Newton method uses the observed behavior of the log-likelihood function and its gradient to make an approximation to

\footnotetext{
${ }^{15}$ More on using order statistics to estimate the lower and upper bound of distributions can be found in Van den Berg and Ridder (1993, 1998) and Donald and Paarsch (1993).
} 
the Hessian matrix using the BFGS iterative updating technique. This method is implemented via a Matlab routine. We use random values for $\lambda$ and $\mu_{1}$ as starting points and estimate the model several times to make sure that the outcome does not depend on the starting values. ${ }^{16}$ Given these estimates of the parameters we can derive the level of search cost $c$ that is consistent with optimal consumer search using equations (10), (11) and (15). Standard errors for $\lambda$ and $\mu_{1}$ are estimated by calculating the analytic Hessian matrix, given the estimates of $\lambda$ and $\mu_{1}$. Standard errors for $r$ and $c$ are calculated using the delta method. ${ }^{17}$

Because the costless and the costly search equilibria are empirically nested, likelihood scores can be directly compared between the two. Since the costly search equilibrium differs from the costless search equilibrium by the addition of an extra parameter, the likelihood score of the costly search equilibrium will always be higher than that of the costless search equilibrium. However, it could be the case that the additional parameter is not justified in terms of a significant improvement in the fit of the model. To formally test this, we perform a Likelihood Ratio $(L R)$ test. Define

$$
L R=-2\left(\ln L L_{1}-\ln L L_{2}\right)
$$

where $L L_{1}$ is the likelihood score of the costless search equilibrium, $L L_{2}$ is the likelihood score of the costly search equilibrium. $L R$ follows a $\chi^{2}$ distribution with degrees of freedom equal to the number of additional parameters in the costly search equilibrium.

The comparison of likelihood scores gives information about the relative performance of the equilibria, but in order to test how well the estimated density function fits the data, we use a chisquared test of fit. This test checks whether the price observations for a given product in a given moment in time are likely to be drawn from the theoretical distribution function. To do this, we divide the range of observed prices into $k$ classes. A comparison of the observed frequency with the estimated hypothetical frequency of prices in the $k$ classes gives information about the goodness of fit. The classical Pearson chi-squared statistic is given by

$$
X^{2}=\sum_{i=1}^{k} \frac{\left(M_{i}-N \varphi_{i}\right)^{2}}{N \varphi_{i}}
$$

\footnotetext{
${ }^{16}$ These random starting values for $\lambda$ and $\mu_{1}$, together with $N, \underline{p}, \bar{p}$ and a price $p_{i}$ are plugged into equation (13) to find the value of $F\left(p_{i}\right)$ that solves this equation; this is done for all prices in the cross-section $p_{i}$. Subsequently, the calculated values of $F(p)$, together with $N, p, \bar{p}$, the vector of remaining prices and the starting values of $\lambda$ and $\mu_{1}$ are plugged into equation (16) to calculate the vector $f(p)$, from which we can calculate $L L$. The BFGS quasi-Newton method then comes with a new $\lambda$ and $\mu_{1}$, from which we calculate a new value for $L L$. This process continues until the optimal $\lambda$ and $\mu_{1}$ are found, i.e., $L L$ is maximized.

${ }^{17}$ If $r$ is a function of the estimated $\lambda$ and $\mu$, then the variance of $r$ is given by $\frac{\partial r}{\partial \theta} \cdot(-H)^{-1} \cdot \frac{\partial r}{\partial \theta}{ }^{\prime}$, where $H$ is the Hessian matrix and $\theta$ is the vector of estimated parameters.
} 
where $M_{i}$ is the observed frequency for class $i, N$ is the total number of price observations and $\varphi_{i}=\int_{z} d F(p)$ is the theoretical probability that a price observation falls in class $i$ with boundary $z$. When $F(p)$ is fully specified, $X^{2}$ follows a $\chi^{2}$ distribution with $k-1$ degrees of freedom. However, in our case $F(p)$ is not completely specified (either $\lambda$, or $\lambda$ and $\mu_{1}$ are estimated). Since we are using maximum likelihood to estimate the parameters, $X^{2}$ does not have an asymptotic $\chi^{2}$ distribution: the distribution of $X^{2}$ is bounded between a $\chi_{k-1}^{2}$ and a $\chi_{k-q-1}^{2}$ variable, where $q$ is the number of estimated parameters (Kendall and Stuart (1973), p. 447). To bypass this uncertainty in degrees of freedom when $F(p)$ is estimated by ordinary maximum likelihood, we shall use the Rao-Robson statistic (Rao and Robson, 1974). The Rao-Robson statistic $R R$ corrects for the uncertainty involved in estimating $F(p)$ and builds up the Pearson statistic $X^{2}$ to $\chi_{k-1}^{2}$. Put more formally,

$$
R R=X^{2}+\left(V^{\prime} B\right)\left(J-B^{\prime} B\right)^{-1}\left(V^{\prime} B\right)^{\prime},
$$

where $X^{2}$ is the Pearson chi-squared statistic, $V^{\prime} B=n^{-\frac{1}{2}}\left(\sum_{i=1}^{k} \frac{M_{i}}{\varphi_{i}} \frac{\partial \varphi_{i}}{\partial \theta_{1}}, \ldots, \frac{M_{i}}{\varphi_{i}} \frac{\partial \varphi_{i}}{\partial \theta_{q}}\right)$, with $\theta$ the vector of parameters to be estimated, $J$ is the Fisher information matrix for $F(\cdot \mid \theta)$, and $B(\theta)$ is the matrix with $(i, j)$ th entry $\varphi_{i}(\theta)^{-\frac{1}{2}} \frac{\partial \varphi_{i}(\theta)}{\partial \theta_{j}}$. $R R$ follows a $\chi_{k-1}^{2}$ distribution. The smaller $R R$, the better the fit is. If the fit is perfect, $R R$ is zero. In calculating $R R$ we shall use equiprobable classes $k$. Although the choice of the number of classes $k$ remains somewhat arbitrary, we will follow the recommendations made by Moore (1986) for a five percent level of significance, i.e., $k$ is taken to be the closest integer to $2 N^{\frac{2}{5}}$.

\subsection{The data}

A market most suitable in terms of the model of the previous section would consist of firms offering a homogeneous product to consumers who demand at most a single unit of the product. Keeping this in mind, we have chosen to focus on the on-line markets for computer hardware and peripherals. In particular, we concentrate on keyboards, memory chips, mice and computer cables. In our view, these markets come quite close to the market outlined above in Section $2 .{ }^{18}$

To streamline the process of collecting data, price observations are collected daily from March till April 2004 on shopper.com, a large American shopbot. ${ }^{19}$ The United States have a relatively

\footnotetext{
${ }^{18}$ Of course, it is clear that these markets have features that are not accounted for in our theoretical model. To mention an example, there are several ways in which a firm can ship a product to a client; this makes the bundle product-shipping a differentiated item. Consumers probably do take these extra costs into account when deciding which store to buy from. However, including shipping and handling fees would complicate matters too much so we abstract from them in what follows.

${ }^{19}$ See http://shopper.cnet.com.
} 
long history of E-commerce. Already in the 1980s products were sold via the Internet. At that time, only of a fraction of the people that nowadays are on-line had access to the Internet. According to Nielsen//NetRatings, in February 2004 three out of four Americans, or more than 200 million, had access to the Internet. ${ }^{20}$ Among people aged between 35 and 54 the Internet access penetration rate - defined as the percentage of people who have access to the Internet, though not necessarily logging on-line during a specific time frame - was even more than eighty percent. As recent figures show, these people get more and more accustomed to on-line shopping. According to the eSpending Report from Goldman Sachs, Harris Interactive and Nielsen//NetRatings, on-line consumers spent $\$ 18.5$ billion (excluding travel) during the 2003 Christmas holiday season, an increase of 35 percent compared to the year before. ${ }^{21}$ With projected on-line revenues of $\$ 1,650$ million during the 2003 Christmas holiday season, the on-line market for computer hardware and peripherals covers a substantial part of the total on-line market.

In an ideal situation, the shopbot would give us the prices of all available on-line stores in the United States. Although shopper.com gives a substantial number of retailers for most products, we realize that there are more on-line stores selling computer hardware and peripherals in the United States than shopper.com actually gives. However, if we assume that the list of prices shopper.com offers is not biased in some sense, this does not pose a problem.

We have collected prices for 91 products in total: 22 keyboards, 22 mice, 22 cables and 25 memory chips. The observations that follow are common to all products so in the remainder of this section we will focus the discussion solely on keyboards. Table 1 presents the summary statistics for the product category keyboards. ${ }^{22}$ The keyboards are sorted by increasing value. Lower quality (valued) keyboards (keyboards with a maximum price below $\$ 30.00$ ) were selected by taking the eleven lowest priced products in the category keyboards on shopper.com, conditional on that at least five shops were selling the product on the first day of data gathering. Higher valued keyboards were selected by taking the eleven most popular products from the category keyboards on shopper.com with a highest price above $\$ 50$ on the first day of data gathering, again only if the number of shops selling the product was at least five. ${ }^{23}$ The horizontal line in Table 1 separates the results for the two groups of products. ${ }^{24}$ As the table shows, for all keyboards there is quite

\footnotetext{
${ }^{20}$ See http://direct.www.nielsen-netratings.com/pr/pr_040318.pdf.

${ }^{21}$ See http://www.nielsen-netratings.com/pr/pr_040105_us.pdf.

${ }^{22}$ Summary statistics for memory chips, mice and cables are skipped to save on space.

${ }^{23}$ We note that 4 products were left out of the analysis subsequently because the number of shops declined to less than three over time.

${ }^{24}$ The same criteria for data selection as well as for the analysis apply to memory chips, mice and computer cables as well.
} 


\begin{tabular}{|c|c|c|c|c|c|c|c|c|c|}
\hline Name Product & $t$ & obs & $N$ & avg & $\min$ & $\max$ & $\max -\min$ & var & $\mathrm{cV}$ \\
\hline Micro Innovations Datapad TKB195S & 38 & 261 & 6.87 & 8.46 & 6.49 & 12.99 & 6.50 & 5.40 & 0.27 \\
\hline BenQ Regular Membrane 52XA & 38 & 266 & 7.00 & 10.05 & 7.74 & 15.63 & 7.89 & 7.23 & 0.27 \\
\hline Labtec Standard Keyboard & 38 & 289 & 7.61 & 10.52 & 7.50 & 16.13 & 8.83 & 12.53 & 0.33 \\
\hline Belkin Standard Keyboard & 38 & 387 & 10.18 & 9.85 & 7.09 & 17.18 & 10.09 & 9.12 & 0.30 \\
\hline Adesso KB9001 & 38 & 192 & 5.05 & 11.17 & 8.54 & 17.18 & 8.64 & 14.56 & 0.34 \\
\hline Key Tronic E03601 (grey) & 38 & 366 & 9.63 & 10.59 & 7.25 & 17.70 & 10.45 & 11.90 & 0.33 \\
\hline Key Tronic E03600 (beige) & 38 & 446 & 11.74 & 10.38 & 6.45 & 18.00 & 11.55 & 11.80 & 0.33 \\
\hline Micro Innovations KB400i & 38 & 473 & 12.45 & 11.65 & 6.99 & 23.38 & 16.39 & 37.00 & 0.52 \\
\hline IBM Wireless Navigator Pro & 38 & 346 & 9.11 & 45.21 & 39.99 & 50.20 & 10.21 & 14.05 & 0.08 \\
\hline Adesso AKB-805MAC & 38 & 431 & 11.34 & 53.38 & 47.38 & 59.99 & 12.62 & 17.30 & 0.08 \\
\hline Microsoft Basic Wireless Optical Desktop & 38 & 595 & 15.66 & 53.34 & 43.46 & 61.99 & 18.83 & 37.73 & 0.11 \\
\hline Logitech Cordless Navigator Duo & 38 & 1028 & 27.05 & 63.91 & 46.39 & 79.99 & 33.60 & 86.06 & 0.15 \\
\hline Logitech Cordless MX Duo & 38 & 1254 & 33.00 & 80.81 & 65.58 & 99.99 & 34.41 & 86.94 & 0.12 \\
\hline Microsoft Wireless Optical Desktop Elite & 38 & 839 & 22.08 & 84.65 & 71.95 & 99.99 & 28.04 & 54.46 & 0.09 \\
\hline Microsoft Wireless Optical Desktop for Bluetooth & 38 & 712 & 18.74 & 95.39 & 76.78 & 139.90 & 63.12 & 299.50 & 0.18 \\
\hline Logitech Cordless Desktop MX for Bluetooth & 38 & 952 & 25.05 & 156.19 & 134.00 & 179.94 & 45.94 & 159.94 & 0.08 \\
\hline Gyration Ultra GT Full-Size Keyboard Suite & 38 & 677 & 17.82 & 110.82 & 88.33 & 180.00 & 91.67 & 802.25 & 0.26 \\
\hline Gyration Ultra GT Compact Keyboard Suite & 38 & 676 & 17.79 & 127.75 & 106.13 & 181.20 & 75.07 & 618.72 & 0.19 \\
\hline Logitech DiNovo Media Desktop & 38 & 739 & 19.45 & 219.67 & 188.89 & 263.12 & 74.22 & 415.99 & 0.09 \\
\hline
\end{tabular}

Table 1: Summary statistics for product category "keyboards"

a big difference between the maximum and the minimum price found. Other indicators of price dispersion, like variance and the coefficient of variation (squared root of the variance divided by the average price), also point towards substantial price dispersion. This implies that the gains from search are large in these markets. Notice that the coefficient of variation, which is a scaled indicator of price dispersion, seems to be decreasing in the value of the product.

Figure 1 presents price-histograms for two keyboards (including mouse) collected on March 1, 2004. Also this figure shows that there is substantial price dispersion, with some prices being twice as high as others. The histogram for 'Microsoft Wireless Optical Desktop for Bluetooth' represented by Graph 1(a) shows a large mass of shops quoting prices relatively low; by contrast, Graph 1(b) for 'Microsoft Basic Wireless Optical Desktop' shows a spike on the right side of the graph, indicating that for this keyboard shops price less competitively.

\subsection{Results}

The results for the different product categories are, from the point of view of the purpose of testing the two search equilibria, quite similar to each other. As we do not intend to give a detailed description of the different markets, we have decided to show the results of the estimation procedure for one subcategory, namely keyboards, in the main text of the paper. The results for the other product categories, i.e. memory chips, mice and computer cables, can be found in the appendix.

Consider first the estimates of the parameters of the costless search equilibrium. The results 


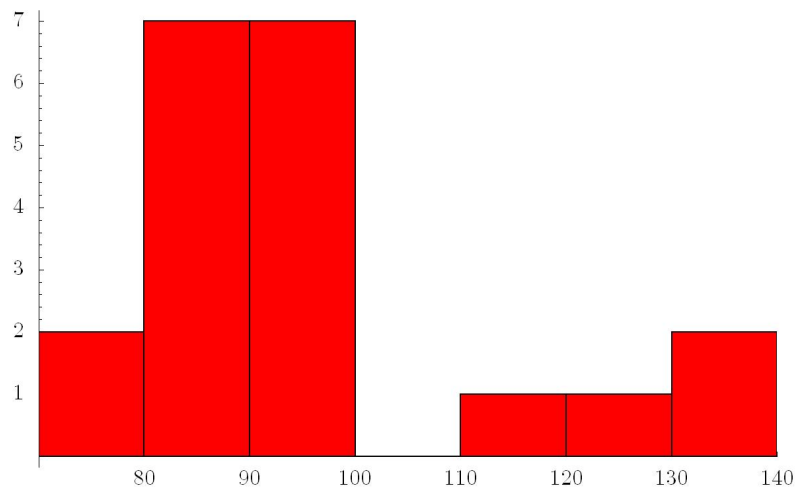

(a) Microsoft Wireless Optical Desktop for Bluetooth

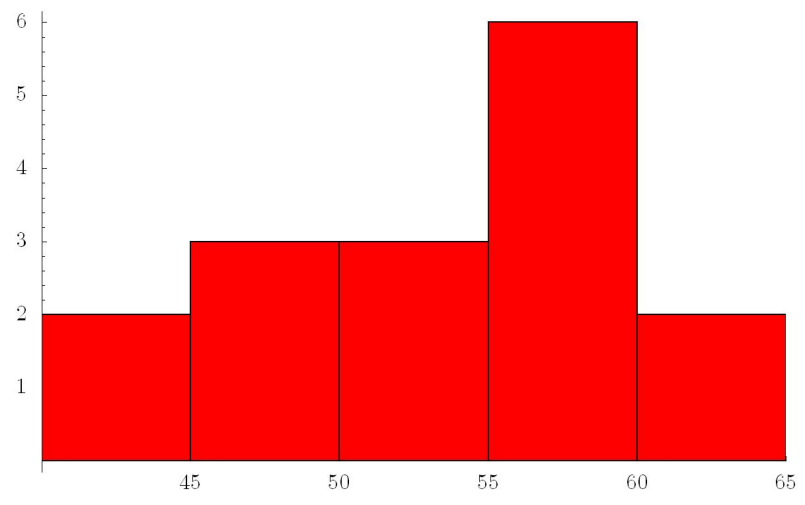

(b) Microsoft Basic Wireless Optical Desktop

Figure 1: Histograms (March 1, 2004)

are presented in Table 2. As the table shows, estimates of the share of consumers using a shopbot $\lambda$ range between 0.65 and 0.95 and are highly significant. We note that these estimates seem quite high on the basis of findings by other authors (although somewhat outdated, Whelan (2001) finds that around 36 percent of on-line shoppers can be classified as bargain hunters). Using the estimates of $\lambda$, we can calculate estimates of unit $\operatorname{costs} r$ and consumer search costs $c$. As Table 1 shows, in most cases unit cost $r$ is close to the lower bound of the price distribution $\underline{p}$, which means that shops quoting low prices have quite small margins. The search costs that are consistent with the sequential search model, denoted $c^{S}$ in the Table, vary between $\$ 2.95$ and $\$ 23.87$ and seem to be increasing in the value of the product. The lowest search costs capable of rationalizing the costless search equilibrium in the non-sequential case, denoted $c^{N S}$ in the Table, are uniformly lower.

The Rao-Robson test statistics show that for almost half of the lower valued keyboards the null hypothesis that the observed prices are generated from a costless search equilibrium cannot be rejected; however, for higher valued keyboards, the costless search equilibrium always performs poorly. ${ }^{25}$ The discussion of the theoretical model, especially the one on the non-sequential search model, gives us a possible explanation for this observation: the higher $v-r$, the less likely the costless search equilibrium is. However, since Table 1 reveals that $v-r$ is highly correlated with $N$, it could also be the case that the likelihood of the costless search equilibrium decreases in $N$. We note that the high correlation between $N$ and $v-r$ is natural in these models, since products with higher absolute margins should attract new entrants.

\footnotetext{
${ }^{25}$ We note that also according to the Kolmogorov-Smirnov test (results not presented here), which is calculated as the greatest discrepancy between the observed and expected cumulative distribution function, the costless search equilibrium performs much better for higher valued keyboards than for lower valued keyboards.
} 

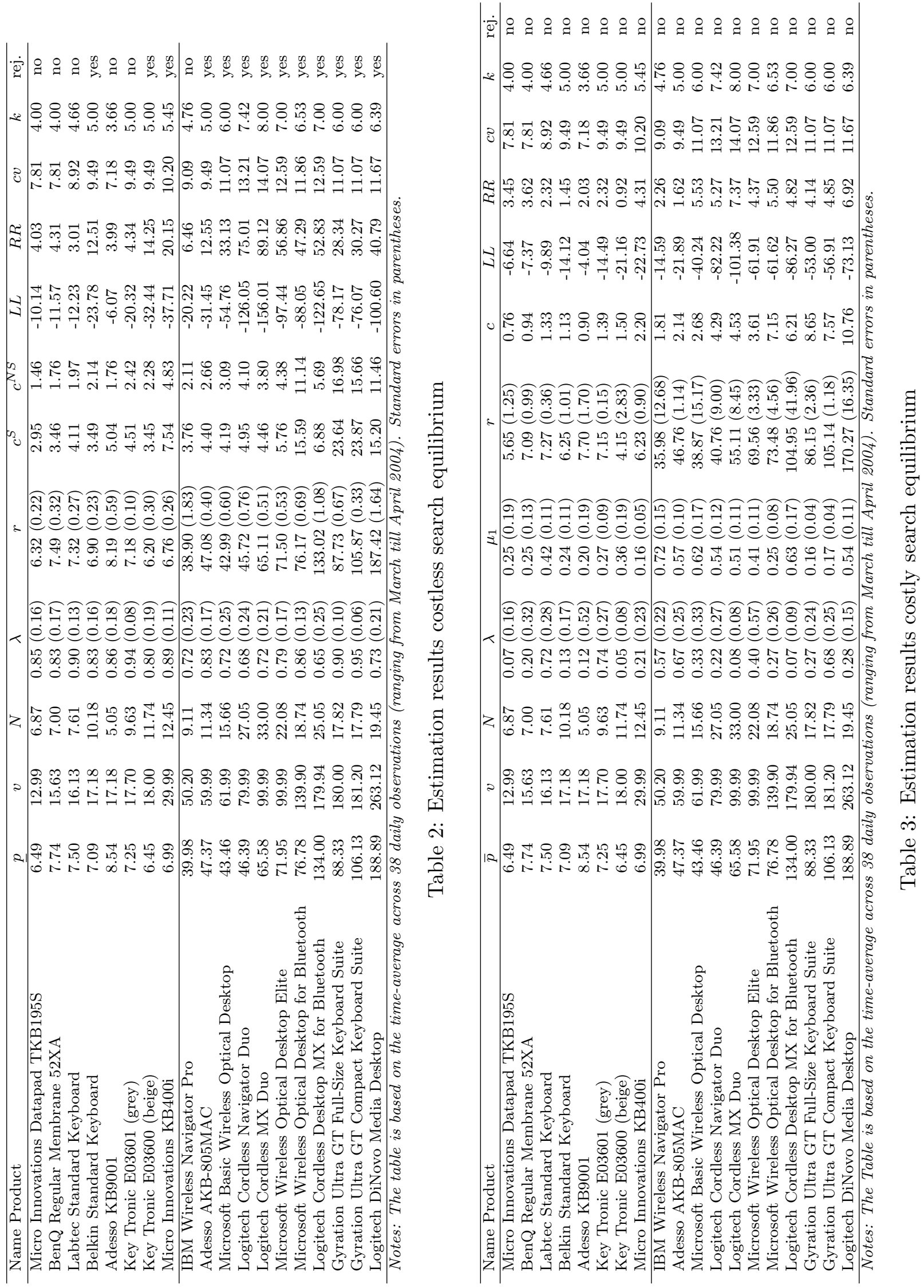
We now turn to discuss the estimation results of the costly search equilibrium. Table 3 gives the results of the estimation procedure and Rao-Robson chi-squared test for the costly search equilibrium. Estimates of $\lambda$ range from 0.05 to 0.74 across keyboards and are much lower than previous estimates of $\lambda$ for the costless search equilibrium. Estimates of $\mu_{1}$ range between 0.16 and 0.72 and are on average highly significant. Estimates of marginal costs $r$ are on average lower than under costless search, which suggests that retailers' price-to-cost margins in the equilibrium with costly search are higher than those in the equilibrium with costless search. The estimated values of the search cost parameter $c$ are much lower under costly search than under costless search, which is what one would expect given the theoretical analysis above. Moreover, we notice that search costs for higher valued keyboards are again somewhat higher than for the rest of the products.

\begin{tabular}{lcccc}
\hline Name Product & $L R$ & $p$-value & rej. 5\% & rej. 1\% \\
\hline Micro Innovations Datapad TKB195S & 7.00 & 0.008 & yes & yes \\
BenQ Regular Membrane 52XA & 8.40 & 0.004 & yes & yes \\
Labtec Standard Keyboard & 4.67 & 0.031 & yes & no \\
Belkin Standard Keyboard & 19.32 & 0.000 & yes & yes \\
Adesso KB9001 & 4.07 & 0.044 & yes & no \\
Key Tronic E03601 (grey) & 11.67 & 0.001 & yes & yes \\
Key Tronic E03600 (beige) & 22.55 & 0.000 & yes & yes \\
Micro Innovations KB400i & 29.97 & 0.000 & yes & yes \\
IBM Wireless Navigator Pro & 11.26 & 0.001 & yes & yes \\
Adesso AKB-805MAC & 19.11 & 0.000 & yes & yes \\
Microsoft Basic Wireless Optical Desktop & 29.06 & 0.000 & yes & yes \\
Logitech Cordless Navigator Duo & 87.65 & 0.000 & yes & yes \\
Logitech Cordless MX Duo & 109.27 & 0.000 & yes & yes \\
Microsoft Wireless Optical Desktop Elite & 71.06 & 0.000 & yes & yes \\
Microsoft Wireless Optical Desktop for Bluetooth & 52.85 & 0.000 & yes & yes \\
Logitech Cordless Desktop MX for Bluetooth & 72.76 & 0.000 & yes & yes \\
Gyration Ultra GT Full-Size Keyboard Suite & 50.34 & 0.000 & yes & yes \\
Gyration Ultra GT Compact Keyboard Suite & 38.31 & 0.000 & yes & yes \\
Logitech DiNovo Media Desktop & 54.94 & 0.000 & yes & yes \\
\hline
\end{tabular}

Table 4: Likelihood Ratio Test Results

The Rao-Robson chi-squared statistics indicate that the costly search equilibrium serves as a good approximation of reality for all keyboards. All the keyboards have a Rao-Robson statistic that is below the critical value corresponding to a $5 \%$ level of significance. This means that for $100 \%$ of the keyboards, the null hypothesis that the observed prices come from the estimated theoretical distribution function $F(p)$ with costly search cannot be rejected. ${ }^{26}$

The $L R$ test results presented in Table 4 formalize what is already indicated by the comparison of the Rao-Robson statistics between the costless search equilibrium and the costly search equilibrium:

${ }^{26}$ This also holds according to Kolmogorov-Smirnov test results. 
the latter outperforms the former one. At a $5 \%$ level of significance, the null hypothesis that the equilibria are equal is rejected for all keyboards; at a $1 \%$ level of significance the costly search equilibrium performs better than the costless search equilibrium for all but two keyboards.

Figure 2 gives examples of how the estimated theoretical distribution functions match observed price data. The thick curves in the graphs represent the empirical distribution function of prices for three different products collected on March 1, 2004, while the dotted curves give the estimated theoretical distribution functions for respectively the costless search equilibrium and the costly search equilibrium. The graphs reveal that the costly search equilibrium outperforms the costless search one for all three products. However, graph 2(e), and, to a lesser extent graph 2(c), show that the costless search equilibrium can generate satisfying results, given that $v$ (and $N$ ) are low.

Summing up, the estimates obtained for the costly search equilibrium explain the observed data remarkably well for almost all products. The costless search equilibrium is a good approximation of retailer behavior as well, provided that the relative value of the purchase is low.

\section{Conclusion}

This paper has examined the empirical predictions that come out of a simple oligopolistic pricing game in the presence of consumer search. Firms were all identical and set prices to maximize profits; consumers differed in that some are fully informed, while others are uninformed. We have seen that different equilibria can arise for different parameter constellations. These equilibria are all characterized by price dispersion and we have distinguished between them in terms of the intensity with which consumers search. In a costless search equilibrium, uninformed consumers search for one price only. This type of equilibrium can arise in both the sequential and non-sequential search setting. In a costly search equilibrium, uninformed consumers randomize between searching for one and two prices. This equilibrium arises when consumers search non-sequentially and search costs are sufficiently low.

The theoretical restrictions that firm and consumer equilibrium behavior yield have been used to estimate the equilibria. We have gathered price data for computer hardware and peripherals; the price observations have been downloaded from an American based search engine. The main conclusion we have drawn is that the costless search equilibrium only generates satisfying results when the value of the purchase (and thus the number of firms) is low, while the costly search equilibrium outperforms the alternative equilibrium in all cases. Given the simplicity of the model, the estimated fit of the costly search equilibrium to the data is remarkably good. 


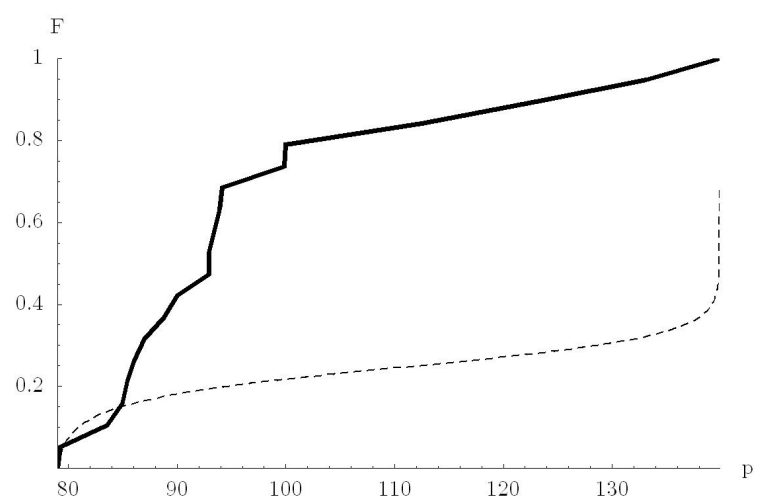

(a) Costless search - Microsoft Wireless Optical Desktop for Bluetooth $(N=20, v=139.90)$

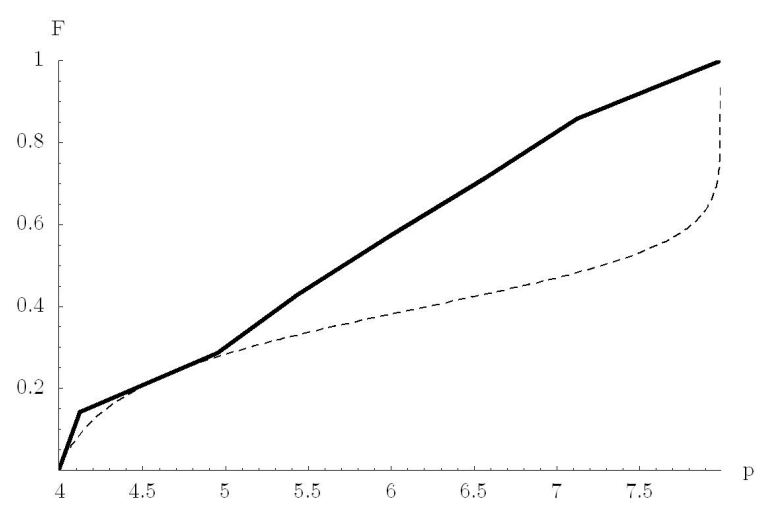

(c) Costless search - Micro PS2 Comfort Mouse $(N=$ $8, v=7.99)$

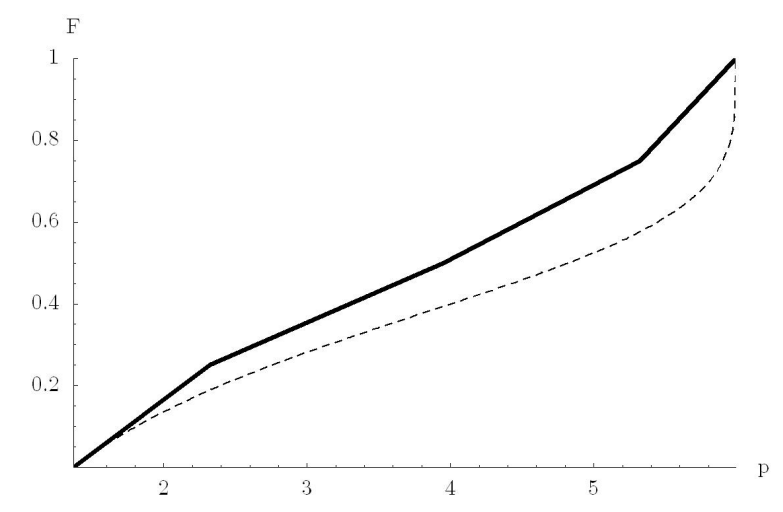

(e) Costless search - StarTech MXT100 $(N=5, v=$ $5.99)$

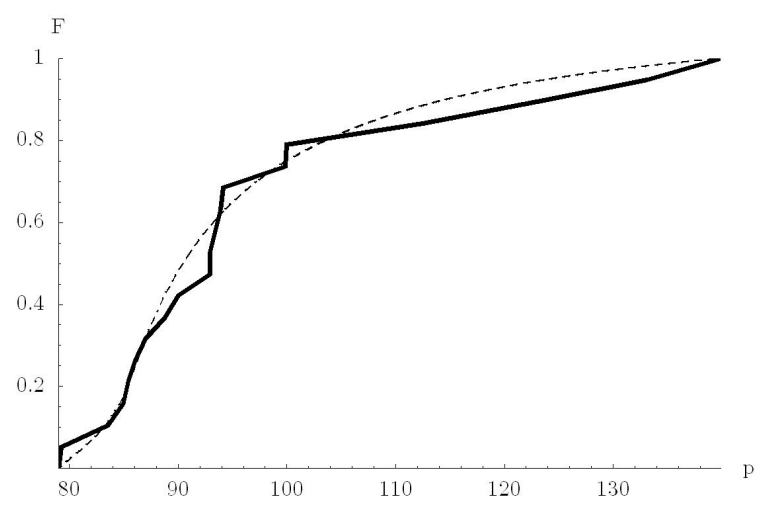

(b) Costly search - Microsoft Wireless Optical Desktop for Bluetooth $(N=20, v=139.90)$

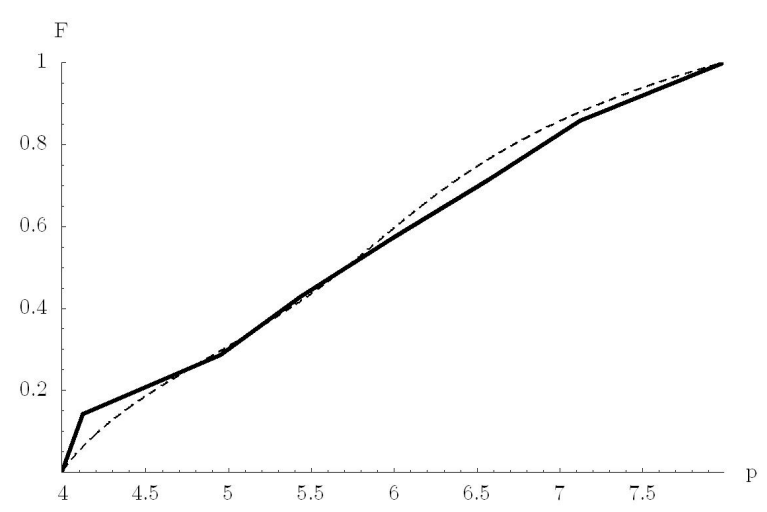

(d) Costly search - Micro PS2 Comfort Mouse $(N=$ $8, v=7.99)$

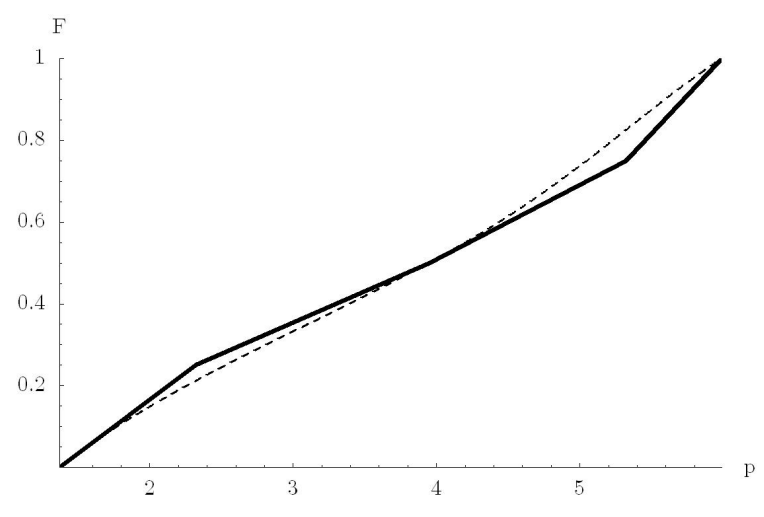

(f) Costly search - StarTech MXT100 $(N=5, v=$ $5.99)$

Figure 2: Fit estimated theoretical cumulative distribution functions (March 1, 2004) 


\section{References}

[1] Eric Abrams, Martin Sefton and Abdullah Yavas: "An Expirimental Comparison of Two Search Models," Economic Theory 16, 735-49, 2000.

[2] Daron Acemoglu and Robert Shimer: "Wage and Technology Dispersion," Review of Economic Studies 67, 585-608, 2000.

[3] Michael R. Baye, Dan Kovenock and Casper de Vries: "It Takes Two to Tango: Equilibria in a Model of Sales", Games and Economic Behavior 4, 493-510, 1992.

[4] Michael R. Baye, John Morgan and Patrick Scholten: "Price Dispersion in the Large and in the Small: Evidence from an Internet Price Comparison Site," Journal of Industrial Economics, forthcoming.

[5] Michael R. Baye and John Morgan: "Price Dispersion in the Lab and on the Internet: Theory and Evidence," Rand Journal of Economics, forthcoming.

[6] Gerard J. van den Berg and Geert Ridder: "An Empirical Equilibrium Search Model of the Labor Market," Econometrica 66, 1183-221, 1998.

[7] Gerard J. van den Berg and Geert Ridder: "On the Estimation of Equilibrium Search Models from Panel Data," in: Jan C. van Ours, Gerard A. Pfann and Geert Ridder (Editors), Labor Demand and Equilibrium Wage Formation, Amsterdam: North-Holland, 1993.

[8] Jeffrey Brown and Austan Goolsbee: "Does the Internet Make Markets More Competitive? Evidence from the Life Insurance Industry," Journal of Political Economy 110, 481-507, 2002.

[9] Erik Brynjolfsson and Michael Smith: "Frictionless Commerce? A Comparison of Internet and Conventional Retailers," Management Science 46, 563-85, 2000.

[10] Kenneth Burdett and Kenneth L. Judd: "Equilibrium Price Dispersion," Econometrica 51, 955-69, 1983.

[11] Timothy N. Cason and Daniel Friedman: "Buyer Search and Price Dispersion: a Laboratory Study," Journal of Economic Theory 112, 232-60, 2003.

[12] Karen Clay, Ramayya Krishnan and Eric Wolff: "Prices and Price Dispersion on the Web: Evidence from the On-line Book Industry," Journal of Industrial Economics 49, 521-39, 2001. 
[13] Douglas D. Davis and Charles A. Holt: "Consumer Search Costs and Market Performance," Economic Inquiry 34, 133-51, 1996.

[14] Peter Diamond: "A Model of Price Adjustment," Journal of Economic Theory 3, 156-68, 1971.

[15] Stephen G. Donald and Harry J. Paarsch: "Piecewise Pseudo-Maximum Likelihood Estimation in Empirical Models of Auctions," International Economic Review 34, 121-48, 1993.

[16] Martin Dufwenberg and Uri Gneezy: "Price Competition and Market Concentration: An Experimental Study," CentER Discussion Paper No. 9827, March, 1998.

[17] Chaim Fershtman and Arthur Fishman: "Price Cycles and Booms: Dynamic Search Equilibrium," American Economic Review 82, 1221-33, 1992.

[18] Han Hong and Matthew Shum: "Can Search Costs Rationalize Equilibrium Price Dispersion in On-line Markets?" mimeo, Duke University, 2004.

[19] Maarten C. W. Janssen and José Luis Moraga-González: "Strategic Pricing, Consumer Search and the Number of Firms," forthcoming in the Review of Economic Studies.

[20] Maarten C. W. Janssen, José Luis Moraga-González and Matthijs R. Wildenbeest: “A Note on Costly Sequential Search and Oligopoly Pricing," Tinbergen Institute Discussion Paper TI 2004-068/1, The Netherlands, June 2004.

[21] Eric J. Johnson, Wendy W. Moe, Peter S. Fader, Steven Bellman and Gerald L. Lohse: "On the Depth and Dynamics of On-line Search Behavior," Management Science 50-3, 299-308, 2004 .

[22] Maurice G. Kendall and Alan Stuart, The Advanced Theory of Statistics, vol. 2, London: Charles Griffin \& Company Limited, 1973.

[23] Nicholas M. Kiefer and George R. Neumann: "Wage Dispersion with Homogeneity: The Empirical Equilibrium Search Model," in: Henning Bunzel, Peter Jensen and Niels WestergårdNielsen (Editors), Panel Data and Labour Market Dynamics, Amsterdam: North-Holland, 1993.

[24] Preston R. McAfee: "Multiproduct Equilibrium Price Dispersion," Journal of Economic Theory $67,83-105,1995$. 
[25] David S. Moore: "Tests of Chi-Squared Type," in: Ralph B. D'Agostino and Michael A. Stephens (Editors), Goodness-of-Fit Techniques, New York: Marcel Dekker, 1986.

[26] Peter Morgan and Richard Manning: "Optimal Search," Econometrica 53, 923-44, 1985.

[27] John Morgan, Henrik Orzen and Martin Sefton: "An Experimental Study of Price Dispersion," mimeo, 2003.

[28] K.C. Rao and D.S. Robson: "A Chi-Square Statistic for Goodness-of-Fit within the Exponential Family," Communications in Statistics 3, 1139-53, 1974.

[29] Jeniffer F. Reinganum: "A Simple Model of Equilibrium Price Dispersion," Journal of Political Economy 87, 851-58, 1979.

[30] Rafael Rob: "Equilibrium Price Distributions," Review of Economic Studies 52, 487-504, 1985.

[31] Alan T. Sorensen: "Equilibrium Price Dispersion in Retail Markets for Prescription Drugs," Journal of Political Economy 108, 833-50, 2000.

[32] Alan T. Sorensen: "Price Dispersion and Heterogeneous Consumer Search for Retail Prescription Drugs," NBER Working Paper w8548, 2001.

[33] Dale O. Stahl: "Oligopolistic Pricing with Sequential Consumer Search," American Economic Review 79, 700-12, 1989.

[34] Dale O. Stahl: "Oligopolistic Pricing with Heterogeneous Consumer Search," International Journal of Industrial Organization 14, 243-68, 1996.

[35] Hal R. Varian: "A Model of Sales," American Economic Review 70, 651-59, 1980.

[36] J. Miguel Villas-Boas: "Models of Competitive Price Promotions: Some Empirical Evidence from the Coffee and Saltine Crackers Markets," Journal of Economics and Management Strategy 4, 85-107, 1995.

[37] David Whelan: "A Tale of Two Consumers," American Demographics 23, 54-7, 2001. 

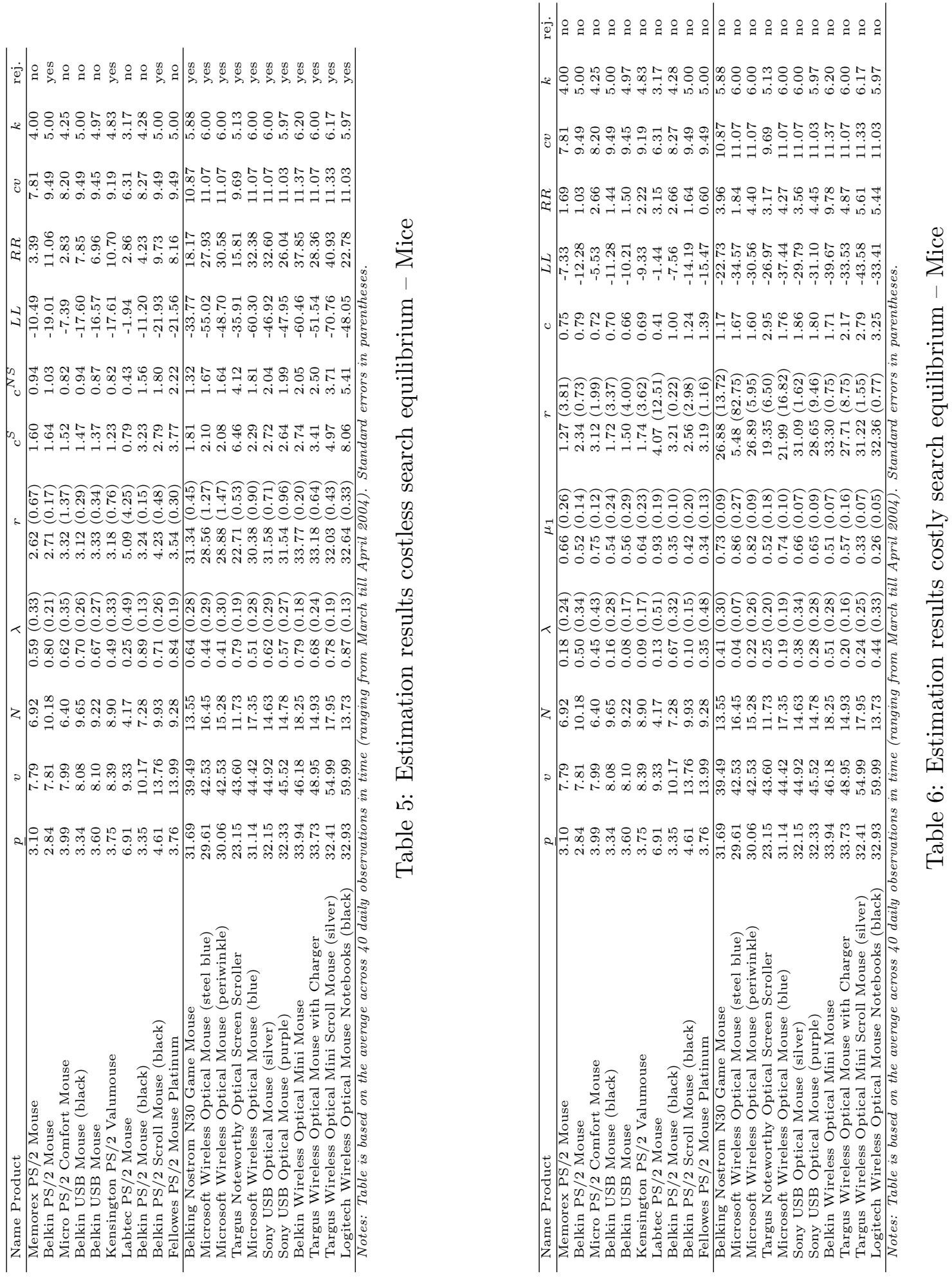


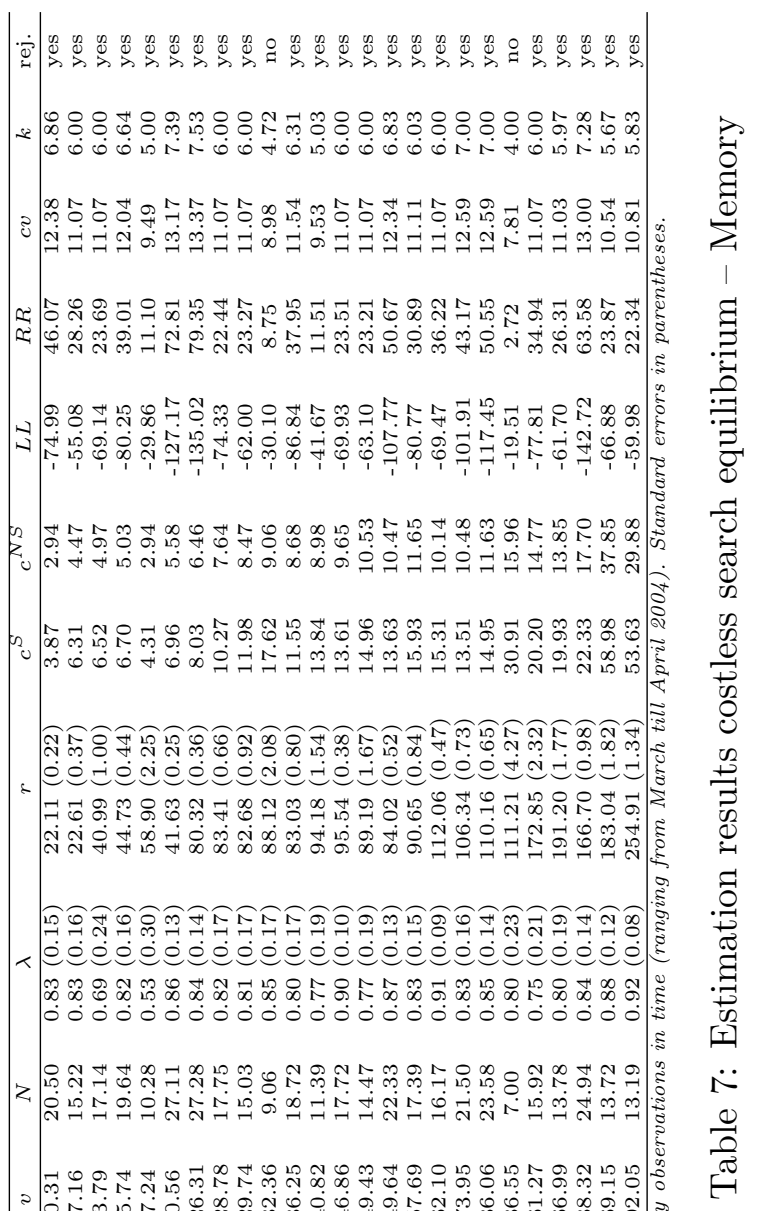

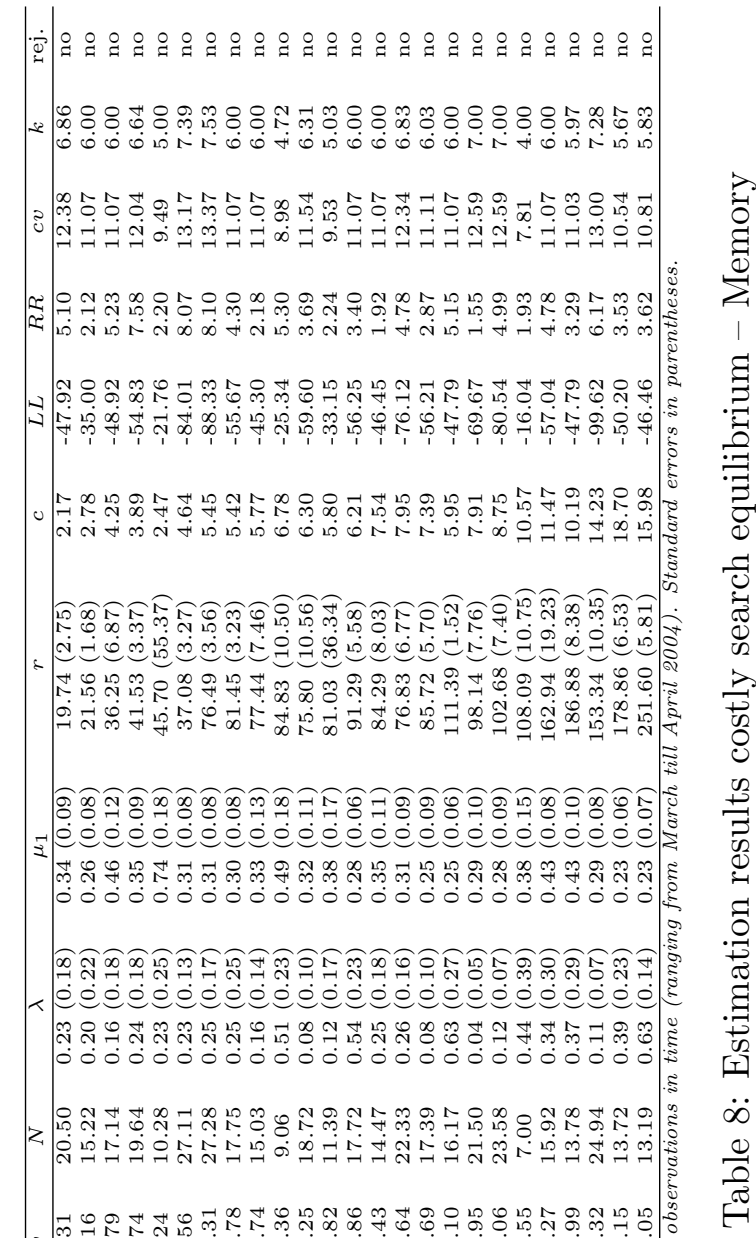
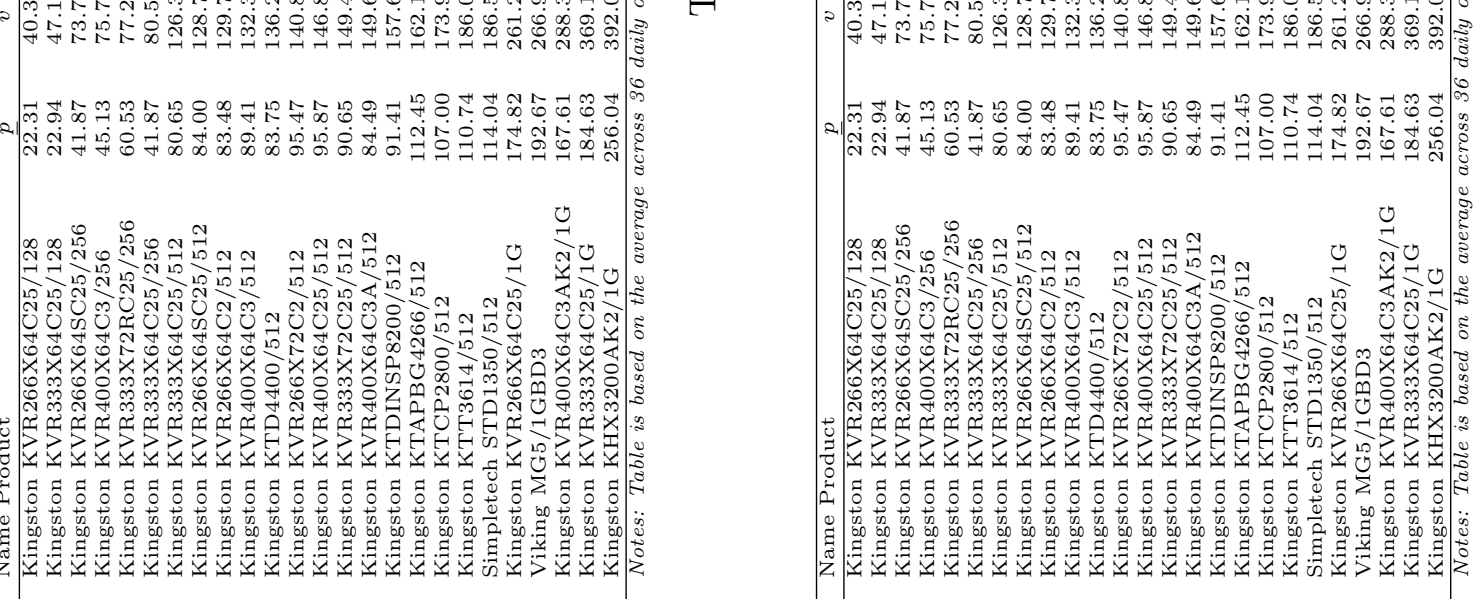

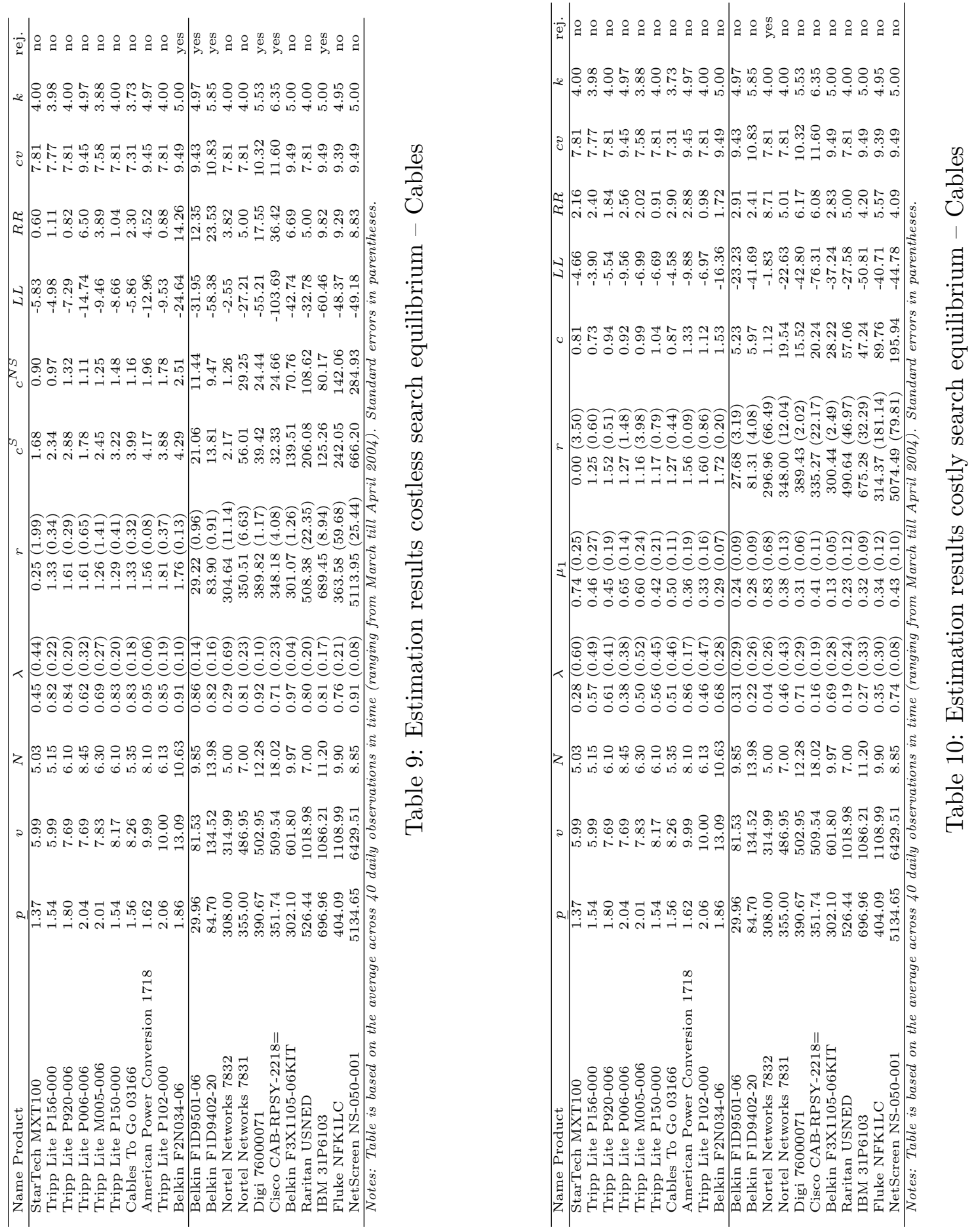


\begin{tabular}{|c|c|c|c|c|}
\hline Name Product & $L R$ & $p$-value & rej. $5 \%$ & rej. $1 \%$ \\
\hline Memorex PS/2 Mouse & 6.32 & 0.012 & yes & no \\
\hline Belkin PS/2 Mouse & 13.46 & 0.000 & yes & yes \\
\hline Micro PS/2 Comfort Mouse & 3.73 & 0.053 & no & no \\
\hline Belkin USB Mouse (black) & 12.64 & 0.000 & yes & yes \\
\hline Belkin USB Mouse & 12.72 & 0.000 & yes & yes \\
\hline Kensington PS/2 Valumouse & 16.56 & 0.000 & yes & yes \\
\hline Labtec PS/2 Mouse & 1.00 & 0.317 & no & no \\
\hline Belkin PS/2 Mouse (black) & 7.26 & 0.007 & yes & yes \\
\hline Belkin PS /2 Scroll Mouse (black) & 15.46 & 0.000 & yes & yes \\
\hline Fellowes PS/2 Mouse Platinum & 12.17 & 0.000 & yes & yes \\
\hline Belking Nostrom N30 Game Mouse & 22.08 & 0.000 & yes & yes \\
\hline Microsoft Wireless Optical Mouse (steel blue) & 40.90 & 0.000 & yes & yes \\
\hline Microsoft Wireless Optical Mouse (periwinkle) & 36.27 & 0.000 & yes & yes \\
\hline Targus Noteworthy Optical Screen Scroller & 17.89 & 0.000 & yes & yes \\
\hline Microsoft Wireless Optical Mouse (blue) & 45.72 & 0.000 & yes & yes \\
\hline Sony USB Optical Mouse (silver) & 34.27 & 0.000 & yes & yes \\
\hline Sony USB Optical Mouse (purple) & 33.71 & 0.000 & yes & yes \\
\hline Belkin Wireless Optical Mini Mouse & 41.59 & 0.000 & yes & yes \\
\hline Targus Wireless Optical Mouse with Charger & 36.02 & 0.000 & yes & yes \\
\hline Targus Wireless Optical Mini Scroll Mouse (silver) & 54.34 & 0.000 & yes & yes \\
\hline Logitech Wireless Optical Mouse Notebooks (black) & 29.29 & 0.000 & yes & yes \\
\hline Kingston KVR266X64C25/128 & 54.15 & 0.000 & yes & yes \\
\hline Kingston KVR333X64C25/128 & 40.16 & 0.000 & yes & yes \\
\hline Kingston KVR266X64SC25/256 & 40.45 & 0.000 & yes & yes \\
\hline Kingston KVR400X64C3/256 & 50.83 & 0.000 & yes & yes \\
\hline Kingston KVR333X72RC25/256 & 16.19 & 0.000 & yes & yes \\
\hline Kingston KVR333X64C25/256 & 86.32 & 0.000 & yes & yes \\
\hline Kingston KVR333X64C25/512 & 93.39 & 0.000 & yes & yes \\
\hline Kingston KVR266X64SC25/512 & 37.31 & 0.000 & yes & yes \\
\hline Kingston KVR266X64C2/512 & 33.39 & 0.000 & yes & yes \\
\hline Kingston KVR400X64C3/512 & 9.51 & 0.002 & yes & yes \\
\hline Kingston KTD4400/512 & 54.48 & 0.000 & yes & yes \\
\hline Kingston KVR266X72C $2 / 512$ & 17.05 & 0.000 & yes & yes \\
\hline Kingston KVR400X64C25/512 & 27.36 & 0.000 & yes & yes \\
\hline Kingston KVR333X72C25/512 & 33.29 & 0.000 & yes & yes \\
\hline Kingston KVR $400 \mathrm{X} 64 \mathrm{C} 3 \mathrm{~A} / 512$ & 63.30 & 0.000 & yes & yes \\
\hline Kingston KTDINSP8200/512 & 49.11 & 0.000 & yes & yes \\
\hline Kingston KTAPBG4266/512 & 43.35 & 0.000 & yes & yes \\
\hline Kingston KTCP $2800 / 512$ & 64.49 & 0.000 & yes & yes \\
\hline Kingston KTT3614/512 & 73.82 & 0.000 & yes & yes \\
\hline Simpletech STD1350/512 & 6.93 & 0.008 & yes & yes \\
\hline Kingston KVR266X64C25/1G & 41.54 & 0.000 & yes & yes \\
\hline Viking MG5/1GBD3 & 27.82 & 0.000 & yes & yes \\
\hline Kingston KVR400X64C3AK2/1G & 86.19 & 0.000 & yes & yes \\
\hline Kingston KVR333X64C25/1G & 33.36 & 0.000 & yes & yes \\
\hline Kingston KHX3200AK2/1G & 27.04 & 0.000 & yes & yes \\
\hline StarTech MXT100 & 2.34 & 0.126 & no & no \\
\hline Tripp Lite P156-000 & 2.17 & 0.141 & no & no \\
\hline Tripp Lite P920-006 & 3.50 & 0.061 & no & no \\
\hline Tripp Lite P006-006 & 10.36 & 0.001 & yes & yes \\
\hline Tripp Lite M005-006 & 4.95 & 0.026 & yes & no \\
\hline Tripp Lite P150-000 & 3.96 & 0.047 & yes & no \\
\hline Cables To Go 03166 & 2.57 & 0.109 & no & no \\
\hline American Power Conversion 1718 & 6.16 & 0.013 & yes & no \\
\hline Tripp Lite P102-000 & 5.12 & 0.024 & yes & no \\
\hline Belkin F2N034-06 & 16.55 & 0.000 & yes & yes \\
\hline Belkin F1D9501-06 & 17.44 & 0.000 & yes & yes \\
\hline Belkin F1D9402-20 & 33.37 & 0.000 & yes & yes \\
\hline Nortel Networks 7832 & 1.44 & 0.230 & no & no \\
\hline Nortel Networks 7831 & 9.15 & 0.002 & yes & yes \\
\hline Digi 76000071 & 24.82 & 0.000 & yes & yes \\
\hline Cisco CAB-RPSY-2218= & 54.78 & 0.000 & yes & yes \\
\hline Belkin F3X1105-06KIT & 11.00 & 0.001 & yes & yes \\
\hline Raritan USNED & 10.41 & 0.001 & yes & yes \\
\hline IBM 31P6103 & 19.20 & 0.000 & yes & yes \\
\hline Fluke NFK1LC & 15.33 & 0.000 & yes & yes \\
\hline NetScreen NS-050-001 & 8.81 & 0.003 & yes & yes \\
\hline
\end{tabular}

Table 11: Likelihood Ratio Test Results 